\title{
Possible Association between Erectile Dysfunction and Osteoporosis in Men
}

\author{
Murat Dursun ${ }^{1}$, Emin Özbek ${ }^{2}$, Alper Otunctemur², \\ Suleyman Sami Cakir ${ }^{3}$ \\ ${ }^{1}$ Department of Urology, Bahcelievler State Hospital, Istanbul, Turkey; \\ ${ }^{2}$ Department of Urology, Okmeydani Research and Education Hospital, \\ Istanbul, Turkey; \\ ${ }^{3}$ Department of Urology, Bayburt State Hospital, Bayburt, Turkey \\ Received October 26, 2014; Accepted March 12, 2015.
}

Key words: Erectile dysfunction - Osteoporosis - Bone mineral density International Index of Erectile Function

\begin{abstract}
Sexual dysfunction in general and erectile dysfunction (ED) in particular significantly affect men's quality of life. Some patients who have ED, also develop osteoporosis. So, in this study we investigated the relationship between erectile dysfunction and osteoporosis in men. 95 men with erectile dysfunction and 82 men with normal sexual function were included in the study. The men's sexual functions were evaluated by International Index of Erectile Function-5 items (IIEF-5). All men received a Dual Energy X-ray Absorptiometry (DEXA; Hologic) scan to measure bone mineral density (BMD) for osteoporosis. Chi-square test was used for statistical analysis. Mean age was 53.5 (38-69) in ED group and 50.1 (31-69) in control group. In ED group the men have lower T score levels than those of the control group. In conclusion, the men who have erectile dysfunction were at more risk for osteoporosis. The results of the present study demonstrate that the men with erectile dysfunction have low bone mineral density and they are at higher risk for osteoporosis. Because of easy and noninvasive evaluation of osteoporosis, patients with ED should be checked for bone mineral density and osteoporotic male subjects should be evaluated for ED.
\end{abstract}

Mailing Address: Dr. Murat Dursun, Department of Urology, Bahcelievler State Hospital, 34180, Kocasinan Merkez, Bahcelievler, Istanbul, Turkey; Phone: +90 21249670 00; Fax: +90 21249670 00; e-mail:mrt_drsn@hotmail.com 


\section{Introduction}

Sexual dysfunction in general and erectile dysfunction (ED) in particular significantly affects men's quality of life. Erectile dysfunction (ED), the consistent inability over at least 3 months to achieve or maintain penile erection sufficient for satisfactory sexual performance, affects nearly 1 in 3 men older than 50 years (Fisher et al., 2009; Montorsi et al., 2010). It is a multifactorial condition that is estimated to affect more than 150 million men worldwide (Ayta et al., 1999). Because of its high prevalence, profound effect on quality of life, and association with diabetes mellitus and cardiovascular disease, the medical and socioeconomic consequences of ED are substantial (Seftel et al., 2004; Dong et al., 2011).

An erection is a complex event that requires an intact arterial and venous system, normal innervation, normal hormonal factors, and functioning erectile tissue (endothelium). Abnormalities in one or more of these factors can lead to ED. Well-established risk factors for ED include hypertension, hyperlipidemia, diabetes, smoking, low testosterone, alcohol and drug abuse, anemia, trauma to/surgery of the pelvis or spine, coronary arteria disease (CAD), peripheral vascular disease, Peyronie's disease, and depression (Johannes et al., 2000). One of these, testosterone is recognized as an important regulator of sexual desire, spontaneous sexual thoughts, motivation, attentiveness to erotic stimuli, and sexual activity in men (Alexander and Sherwin, 1991; Bhasin et al., 2007). Also, hypogonadism is associated with a myriad of abnormalities, ranging from sarcopenia and osteoporosis to depression and sexual dysfunction (Morales and Heaton, 2003). In the other hand, nitric oxide can play a role in osteoporosis. Nitric oxide (NO) is a free radical which has important effects on bone cell function. The endothelial isoform of nitric oxide synthase (eNOS) is widely expressed in bone on a constitutive basis, whereas inducible NOS is only expressed in response to inflammatory stimuli. It is currently unclear whether neuronal NOS is expressed by bone cells. Pro-inflammatory cytokines such as IL-1 and TNF cause activation of the iNOS pathway in bone cells and NO derived from this pathway potentiates cytokine and inflammation induced bone loss.

Osteoporosis is characterised by low bone mineral density. This structural deterioration can lead to fractures, pain and functional disabilities. These conditions affect patient's health related quality of life. In a previous study, self-reported lifetime prevalence for osteoporosis is $11.9 \%$ in the German population. Women are 3 times more likely to suffer from osteoporosis than men (17.6\% vs. $5.2 \%)$ (Robert-Koch-Institut, 2011). Male patients with osteoporosis have rarely been the focus of previous studies (Dy et al., 2011). Most studies involving males with osteoporosis have addressed prevalence, life time risk and risk factors for osteoporosis-related fractures (Papaioannou et al., 2009), or results of therapeutic interventions (Amin, 2003). Unlike previous studies, in this study we investigated the relationship between erectile dysfunction and osteoporosis in men; also we discussed the probable pathophysiology of these two diseases. 


\section{Material and Methods}

95 men with erectile dysfunction and 82 normal men for sexual function were included in the study. Men with erectile dysfunction were included into group 1 and the other men formed group 2. The age, comorbidities, body mass indexes (BMI) and previous surgeries were determined. The men who have smoking, alcohol and drug abuse (like androgen therapy), trauma to/surgery of the pelvis or spine, Peyronie's disease and depression were excluded from the study.

The men's sexual functions were evaluated by International Index of Erectile Function-5 items (IIEF-5). The IIEF- 5 included 5 questions which were filled based on the 5-point Likert scale. The points ranged from 5 to 25 and points below 21 indicated erectile dysfunction. Subjects were categorized based on their points into the following groups: severe erectile dysfunction (5 to 10), moderate erectile dysfunction (11 to 15), mild erectile dysfunction (16 to 20 ) and normal (25 to 21).

All men received a Dual Energy X-ray Absorptiometry (DEXA; Hologic) scan to measure BMD. Measurements were made at the lumbar spine (LS; L2-L4 area). T score was calculated for each patient. T score higher than -1 was defined normal, T score between -1 and -2.5 was defined as osteopenia and T score 2.5 or higher denoted osteoporosis. This study was approved by Okmeydani Training and Research Hospital Ethical Committee.

Chi-square test was used for statistical analysis.

\section{Results}

Mean age was 53.5 (38-69) in group 1 and 50.1 (31-69) in group 2, respectively. Mean body mass index was 28.1 (21.4-34.3) in group 1 and 27.6 (20.8-35.6) in group 2; being similar in both groups. 42 men have diabetes mellitus (DM) in group 1 and 15 men in group 2, respectively. There were more men with DM in group 1 , statistically. Other comorbidities were similar between groups. In group 1 , there were 33 men who have T score $\leq-1$ and 62 men who have no osteoporosis or osteopenia. In control group, there were 8 men who have T score $\leq-1$ and 74 men who have no osteoporosis or osteopenia. In group 1 the men have lower T score levels than those of the control group (Table 1). In conclusion, the men who have erectile dysfunction were at higher risk of osteoporosis.

Table 1 - Statistical analysis between groups with chi-square test

\begin{tabular}{lllr}
\hline & ED $(+)$ group & Control group & P-value \\
\hline $\mathrm{n}$ (number of patients) & 95 & 82 & \\
Age (mean and range) & $53.5(38-69)$ & $50.1(31-69)$ & 0.354 \\
BMI (mean and range) & $28.1(21.4-34.3)$ & $27.6(20.8-35.6)$ & 0.098 \\
DM $(+)(\mathrm{n})$ & $42(44 \%)$ & $15(18 \%)$ & $<0.050$ \\
T score $\leq-1(\mathrm{n})$ & $33(35 \%)$ & $8(10 \%)$ & $<0.050$ \\
T score $>-1(\mathrm{n})$ & $62(65 \%)$ & $74(90 \%)$ & $<0.050$ \\
\hline
\end{tabular}

ED - erectile dysfunction; BMI - body mass index; DM - diabetes mellitus 


\section{Discussion}

The results of the present study demonstrate that the men with erectile dysfunction have low bone mineral density and at higher risk of osteoporosis. As we know, penile erection is a complex neurovascular phenomenon that requires an increase in penile arterial inflow, relaxation of cavernosal smooth muscle, and restriction of venous outflow from the penis. Erectile capacity depends on the vascular tone of the penis. Relaxation of corporal smooth muscle is essential for normal erectile function and substantial evidence exists to implicate neuronal and endothelial-derived nitric oxide (NO) as the principal mediator of cavernosal smooth muscle relaxation and penile erection (Burnett et al., 1992; Rajfer et al., 1992). NO released by the endothelium that lines the corpus cavernosum and penile arteries that supply the penis and NO from nonadrenergic, noncholinergic (NANC) nerves binds to the soluble form of guanylate cyclase to increase cavernosal intracellular levels of cyclic 30,50-guanosine monophosphate (cGMP). The enzyme that catalyzes this reaction in the endothelium and NANC neurons is termed nitric oxide synthase (NOS). The constitutive forms of the enzyme, neuronal NOS (nNOS) and endothelial NOS (eNOS), are the principal NOS isoforms involved in the induction of penile erection (Burnett, 1995; GonzalezCadavid et al., 1999). Also, various animal models indicate that elevated levels of $\mathrm{NO}$, as well as elevated levels of NO donors, inhibit bone resorption (Kasten et al., 1994). Nitric oxide has been shown to regulate osteoclasts, which are responsible for bone resorption (Dong et al., 1999). Bone formation and resorption are key processes that are necessary for the constant remodelling that occurs in bone tissue to keep it healthy, and to repair bone micro-damage. The NO donors, have beneficial effects on controlling bone resorption (decreased osteoclastic activity), and have a milder anabolic action on bone formation (i.e. enhanced osteoblastic activity) (Wimalawansa, 2007).

$\mathrm{NO}$ is a free radical involved in vascular relaxation (Palmer et al., 1987). In humans, dilatation of conduit arteries in response to reactive hyperemia is reduced by inhibitors of NO synthesis. Impairment of NO production might cause a fall in radial blood flow in healthy volunteers (Joannides et al., 1995). In dogs, bone blood flow facilitates bone formation and mineralization (Kelly et al., 1990). Because the decreased NO might cause bone loss, NO might play an important role in the pathogenesis of both endothelial dysfunction and osteoporosis.

There is good evidence to suggest that $\mathrm{NO}$ has biphasic effects on osteoclastic bone resorption. Low concentrations of NO have been shown to potentiate IL-1 induced bone resorption, based on the observation that NOS inhibitors inhibit IL-1 induced bone resorption in vitro (Ralston et al., 1995). High concentrations of $\mathrm{NO}$ inhibit osteoclast formation and activity. Experiments using cell and organ cultures have shown that IFNc in combination with IL-1 and/or TNFa strongly induces iNOS expression, leading to very high levels of NO that inhibit bone resorption (Maclntyre et al., 1991; Brandi et al., 1995). This may be the cause 
of relationship between erectile dysfunction and low bone mineral density in our study. We suggested that low NO levels causing osteoporosis and erectile dysfunction are associated. Other mechanism may be the low testosterone levels. Because of the role of testosterone and nitric oxide in erectile function and bone mineral density, relation between ED and bone mineral density is an important issue to work with. ED is multifactorial and with increasing age it is predominantly associated with vascular disease and endothelial dysfunction. However, adequate $T$ concentrations are important for normal sexual function and lower levels affect the central nervous system (with decreased libido, sexual fantasies, and centrally derived spontaneous erections) and peripheral penile erectile mechanisms. ED is also a known symptom of hypogonadism (Tamler and Deveney, 2010) and T supplementation may normalize sexual function. Studies suggest that a high proportion of men $(\sim 52 \%)$ aged $40-70$ years have some degree of ED (Barkin, 2010) and that approximately $10 \%$ of men with ED also have lower than normal T levels. Androgens have an important role in bone metabolism and different conditions associated with hypogonadism are associated with low bone mass. Testosterone regulates male bone metabolism both indirectly by aromatization to estrogens and directly on osteoblasts through the androgen receptor (AR). The net effect of testosterone is to promote periosteal bone formation mostly during puberty and to reduce bone resorption mostly during adult life (Dupree and Dobs, 2004). Moreover, there are connection between testosterone and the vitamin $D$ pathway. It is well known that vitamin $D$ is an important factor in bone metabolism and vitamin $D$ levels $<62.5 \mathrm{mmol} / \mathrm{l}$ are associated with an increased risk of hip fracture in men older than 65 years (Looker and Mussolino, 2008). Testosterone acts indirectly on the parathyroid hormone-vitamin $D$ axis, because testosterone deficiency is related to the reduction of renal $1 \alpha$-hydroxylase activity with a subsequent decrease in 1,25-hydroxy vitamin $D$ concentration, the active form of vitamin $D$ (Francis et al., 1986). There is also positive link between testosterone levels and nitric oxide concentrations (Andric et al., 2010; Marin et al., 2010; Auharek et al., 2012).

Atherosclerosis, erectile dysfunction and osteoporosis share common pathophysiological mechanisms. Because of easy and noninvasive evaluation of osteoporosis, patients with ED should be checked by bone mineral density or osteoporotic male subjects further evaluated for ED. To confirm our suggestion further prospective, randomised studies involving the bone mineral density, nitric oxide and testosterone levels should be carried out in larger patients group.

\section{References}

Alexander, G. M., Sherwin, B. B. (1991) The association between testosterone, sexual arousal, and selective attention for erotic stimuli in men. Horm. Behav. 25, 367-381.

Amin, S. (2003) Male osteoporosis: epidemiology and pathophysiology. Curr. Osteoporos. Rep. 1, 71-77.

Dursun M.; Özbek E.; Otunctemur A.; Cakir S. S. 
Andric, S. A., Janjic, M. M., Stojkov, N. J., Kostic, T. S. (2010) Testosterone-induced modulation of nitric oxide-cGMP signaling pathway and androgenesis in the rat Leydig cells. Biol. Reprod. 83(3), 434-442.

Auharek, S. A., Lara, N. L., Avelar, G. F., Sharpe, R. M., França, L. R. (2012) Effects of inducible nitric oxide synthase (iNOS) deficiency in mice on Sertoli cell proliferation and perinatal testis development. Int. J. Androl. 35(5), 741-751.

Ayta, I. A., McKinlay, J. B., Krane, R. J. (1999) The likely worldwide increase in erectile dysfunction between 1995 and 2025 and some possible policy consequences. BJU Int. 84, 50-56.

Barkin, J. (2010) Erectile dysfunction and low testosterone: cause or an effect? Can. J. Urol. 17, $2-11$ (Suppl. 1).

Bhasin, S., Enzlin, P., Coviello, A., Basson, R. (2007) Sexual dysfunction in men and women with endocrine disorders. Lancet 369, 597-611.

Brandi, M. L., Hukkanen, M., Umeda, T., Moradi-Bidhendi, N., Bianchi, S., Gross, S. S., Polak, J. M., Maclntyre, I. (1995) Bidirectional regulation of osteoclast function by nitric oxide synthase isoforms. Proc. Natl. Acad. Sci. U. S. A. 92, 2954-2958.

Burnett, A. L. (1995) Role of nitric oxide in the physiology of erection. Biol. Reprod. 52, 485-489.

Burnett, A. L., Lowenstein, C. J., Bredt, D. S., Chang, T. S., Snyder, S. H. (1992) Nitric oxide: a physiologic mediator of penile erection. Science 257, 401-403.

Dong, J.Y., Zhang, Y. H., Qin, L. Q. (2011) Erectile dysfunction and risk of cardiovascular disease: meta-analysis of prospective cohort studies. J. Am. Coll. Cardiol. 58, 1378-1385.

Dong, S. S., Williams, J. P., Jordan, S. E., Cornwell, T., Blair, H. C. (1999) Nitric oxide regulation of cGMP production in osteoclasts. J. Cell. Biochem. 73, 478-487.

Dupree, K., Dobs, A. (2004) Osteopenia and male hypogonadism. Rev. Urol. 6, S30-S34 (Suppl. 6).

Dy, C. J., Lamont, L. E., Ton, Q.V., Lane, J. M. (2011) Sex and gender considerations in male patients with osteoporosis. Clin. Orthop. Relat. Res. 469, 1906-1912.

Fisher, W. A., Eardley, I., McCabe, M., Sand, M. (2009) Erectile dysfunction (ED) is a shared sexual concern of couples I: couple conceptions of ED. J. Sex. Med. 6, 2746-2760.

Francis, R. M., Peacock, M., Aaron, J. E., Selby, P. L., Taylor, G. A., Thompson, J., Marshall, D. H., Horsman, A. (1986) Osteoporosis in hypogonadal men: role of decreased plasma 1,25dihydroxyvitamin D, calcium malabsorption, and low bone formation. Bone 7, 261-268.

Gonzalez-Cadavid, N. F., Ignarro, L. J., Rajfer, J. (1999) Nitric oxide and the cyclic GMP system in the penis. Mol. Urol. 3, 51-59.

Joannides, R., Haefeli, W. E., Linder, L., Richard, V., Bakkali, E. H., Thuillez, C., Lüscher, T. F. (1995) Nitric oxide is responsible for flow-dependent dilatation of human peripheral conduit arteries in vivo. Circulation $\mathbf{9 1}$, 1314-1319.

Johannes, C. B., Araujo, A. B., Feldman, H. A., Derby, C. A., Kleinman, K. P., McKinlay, J. B. (2000) Incidence of erectile dysfunction in men 40 to 69 years old: Longitudinal results from the Massachusetts male aging study. J. Urol. 163, 460-463.

Kasten, T. P., Collin-Osdoby, P., Patel, N., Osdoby, P., Krukowski, M., Misko, T. P., Settle, S. L., Currie, M. G., Nickols, G.A. (1994) Potentiation of osteoclast bone-resorption activity by inhibition of nitric oxide synthase. Proc. Natl. Acad. Sci. U. S. A. 91, 3569-3573.

Kelly, P. J., Montgomery, R. J., Bronk, J. T. (1990) Reaction of the circulatory system to injury and regeneration. Clin. Orthop. Relat. Res. 254, 275-288.

Looker, A. C., Mussolino, M. E. (2008) Serum 25-hydroxyvitamin D and hip fracture risk in older U.S. white adults. J. Bone Miner. Res. 23, 143-150.

Maclntyre, I., Zaidi, M., Alam, A. S., Datta, H. K., Moonga, B. S., Lidbury, P. S., Hecker, M., Vane, J. R. (1991) Osteoclastic inhibition: an action of nitric oxide not mediated by cyclic GMP. Proc. Natl. Acad. Sci. U. S.A. 88, 2936-2940. 
Marin, D. P., Bolin, A. P., dos Santos Rde, C., Curi, R., Otton, R. (2010) Testosterone suppresses oxidative stress in human neutrophils. Cell Biochem. Funct. 28(5), 394-402.

Montorsi, F., Adaikan, G., Becher, E., Giuliano, F., Khoury, S., Lue, T. F., Sharlip, I., Althof, S. E., Andersson, K. E., Brock, G., Broderick, G., Burnett, A., Buvat, J., Dean, J., Donatucci, C., Eardley, I., Fugl-Meyer, K. S., Goldstein, I., Hackett, G., Hatzichristou, D., Hellstrom, W., Incrocci, L., Jackson, G., Kadioglu, A., Levine, L., Lewis, R.W., Maggi, M., McCabe, M., McMahon, C. G., Montague, D., Motorsi, P., Mulhall, J., Pfaus, J., Porst, H., Ralph, D., Rosen, R., Rowland, D., Sadeghi-Nejad, H., Shabsigh, R., Stief, C., Vardi,Y., Wallen, K., Wasserman, M. (2010) Summary of the recommendations on sexual dysfunctions in men. J. Sex. Med. 7, 3572-3588.

Morales, A., Heaton, J. P.W. (2003) Hypogonadism and erectile dysfunction: pathophysiological observations and therapeutic outcomes. BJU Int. 92, 896-899.

Palmer, R. M., Ferrige, A. G., Moncada, S. (1987) Nitric oxide release accounts for the biological activity of endothelium-derived relaxing factor. Nature 327, 524-526.

Papaioannou, A., Kennedy, C. C., Cranney, A., Hawker, G., Brown, J. P., Kaiser, S. M., Leslie, W. D., O’Brien, C. J., Sawka, A. M., Khan, A., Siminoski, K., Tarulli, G., Webster, D., McGowan, J., Adachi, J. D. (2009) Risk factors for low BMD in healthy men age 50 years or older: a systematic review. Osteoporos. Int. 20, 507-518.

Rajfer, J., Aronson, W. J., Bush, P. A., Dorey, F. J., Ignarro, L. J. (1992) Nitric oxide as a mediator of relaxation of the corpus cavernosum in response to nonadrenergic, noncholinergic neurotransmission. N. Engl. J. Med. 326, 90-94.

Ralston, S. H., Ho, L. P., Helfrich, M. H., Grabowski, P. S., Johnston, P.W., Benjamin, N. (1995) Nitric oxide: a cytokine-induced regulator of bone resorption. J. Bone Miner. Res. 10, 1040-1049.

Robert-Koch-Institut (2011) Beiträge zur Gesundheitsberichterstattung des Bundes. Daten und Fakten: Ergebnisse der Studie “Gesundheit in Deutschland aktuell”. Available at: http://www.gbe-bund.de

Seftel, A. D., Sun, P., Swindle, R. (2004) The prevalence of hypertension, hyperlipidemia, diabetes mellitus and depression in men with erectile dysfunction. J. Urol. 171, 2341-2345.

Tamler, R., Deveney, T. (2010) Hypogonadism, erectile dysfunction, and type 2 diabetes mellitus: what the clinician needs to know. Postgrad. Med. 122, 165-175.

Wimalawansa, S. J. (2007) Rationale for using nitric oxide donor therapy for prevention of bone loss and treatment of osteoporosis in humans. Ann. N.Y.Acad. Sci. 1117, 283-297.

Dursun M.; Özbek E.; Otunctemur A.; Cakir S. S. 